\title{
A flexible strategy for immobilizing redox-active compounds using in situ generation of diazonium salts. Investigations of the blocking and catalytic properties of the layers.
}

\author{
Jean-Marc Noël, ${ }^{\dagger}$ Béatrice Sjöberg, ${ }^{\dagger}$ Rémi Marsac, ${ }^{\dagger}$ Dodzi Zigah, ${ }^{\dagger}$ Jean-François Bergamini, ${ }^{\dagger}$ \\ Aifang Wang, ${ }^{\dagger}$ Stéphane Rigaut, ${ }^{\dagger}$ Philippe Hapiot, ${ }^{\dagger *}$ Corinne Lagrost ${ }^{\dagger *}$
}

Laboratoire Sciences Chimiques de Rennes, Equipe MaCSE, UMR CNRS 6226, Université de Rennes 1, campus de Beaulieu, 35042 Rennes, France

Laboratoire Sciences Chimiques de Rennes, Equipe OM2, UMR CNRS 6226, Université de Rennes 1, campus de Beaulieu, 35042 Rennes, France

\begin{abstract}
A versatile two-step method is developed to covalently immobilize redox-active molecules onto carbon surfaces. First, a robust anchoring platform is grafted onto surfaces by electrochemical reduction of aryl diazonium salts in situ generated. Depending on the nature of the layer termini, $-\mathrm{COOH}$ or $-\mathrm{NH}_{2}$, a further chemical coupling involving ferrocenemethylamine or ferrocene carboxylic acid derivatives leads to the covalent binding of ferrocene centers. The chemical strategy using acyl chloride activation is efficient and flexible since it can be applied either to surface-reactive end groups or to reactive species in solution. Cyclic voltammetry analyses point to the covalent binding of ferrocene units restricted to the upper layers of the underlying aryl films while AFM measurements show a lost of compactness of the layers after the chemical attachment of ferrocene centers. The preparation conditions of the anchoring layers were found to determine the interfacial properties of the resulted ferrocenyl-modified electrodes. The ferrocene units promoted effective redox mediation providing that the free redox probes are adequately chosen (i.e. $v s$. size/formal potential) and the underlying layers exhibit strong blocking properties. For anchoring films with weaker blocking effect, the coexistence of two distinct phenomena, redox mediation and $\mathrm{ET}$ at pinholes could be evidenced.
\end{abstract}

\footnotetext{
${ }^{\dagger}$ Equipe MaCSE

* Equipe OM2

*Corresponding authors
} 


\section{Introduction}

Control over functionalization of conducting or semiconducting surfaces with biological, redox-active and photochemical sensitive molecules is a critical component for a wide series of applications including molecular (bio-)electronics, catalysis, energy conversion, and chemical and biological sensing. Of central interest is the development of versatile routes for achieving a suitable derivatization of surface materials. The most popular method for surface modification makes use of thiolates self-assembled monolayers on gold. ${ }^{1}$ However, this method suffers from a number of limitations, such as rather slow formation kinetics, a narrow electrochemical potential window and a poor chemical stability that may hamper subsequent coupling with the layer. To overcome these drawbacks, a surface chemistry method yielding a robust covalent attachment to the electrode surface is then highly desirable. In this connection, the electrochemical reduction of aryldiazonium salts, first reported by Pinson et al., ${ }^{2}$ has been proven to be an excellent method to irreversibly attach molecules onto a variety of conducting substrates, especially carbon surface. ${ }^{3-9}$ Diazonium ion reduction has several advantages that make it attractive for surface modification. First, diazonium salts can be easily generated in situ from the corresponding amines with $\mathrm{NaNO}_{2}$ in aqueous $\mathrm{HCl},{ }^{10}$ or in acetonitrile containing supporting salts, ${ }^{11}$ sparing the isolation of the phenyl diazonium reagents. High surface coverages, promoting "self-patching" film formation, are readily obtained. ${ }^{12}$ For sufficiently high diazonium concentration and sufficiently long electrolysis time, the electrochemical reduction of aryl diazonium salts at glassy carbon surfaces was found to be a self-limiting process, with the limiting surface coverage depending on the electrolysis potential. ${ }^{13}$ Such experimental conditions allow the reproducible fabrication of films with particular barrier properties simply by controlling the electrolysis potential. Lastly, the $\mathrm{C}-\mathrm{C}$ bond that is formed between the phenyl radical and the surface is robust, stable for long-term storage, and persists upon sonication in aggressive solvents. ${ }^{7,8}$ Further chemical modification can be then performed through specific substituents present on the aromatic ring and used to bond various active molecules. Several chemical routes were successfully applied for functionalizing the resulting aryl layers. While the carbodiimide chemistry is by far the most widely used strategy because of mild experimental conditions, ${ }^{14-19}$ other routes were also described including the reaction between grafted amino group and acid anhydride, ${ }^{10}$ click chemistry, ${ }^{20} \mathrm{~N}$-phenylmaleimide terminated layers reacting with thiol-tagged molecules, ${ }^{21}$ or coupling between amino groups and epoxy groups. ${ }^{22}$ 
In this work, an alternative strategy based on the efficient reactivity of acyl chloride function towards amino groups is used to form an amide linkage between the anchoring platform and the desired active molecules. ${ }^{23-28}$ Herein, the synthetic approach was found to be particularly flexible since the acyl chloride activation can be efficiently applied either to the surface-reactive end groups or to the reactive species in solution. Worth is noting that the procedure is useful for reaction with immobilized aniline which is generally poorly reactive. The modification of the glassy carbon electrodes was achieved in two steps. First, anchoring layers bearing either $-\mathrm{COOH}$ or $-\mathrm{NH}_{2}$ termini were obtained from the electroreduction of the corresponding diazonium salts. The second step using the acyl chloride activation allowed the covalent immobilization of active molecules onto the anchoring layers. As active molecules, ferrocene moieties were chosen. Owing to their attractive electrochemical characteristics (fast electron transfer, low oxidation potential, stability), introduction of ferrocene units as redox active components can serve different purposes such as electroanalysis, biosensing devices and electrocatalysis.

Besides describing a versatile method for the robust binding of active molecules onto electrodes, the aim of the paper is to study how the interfacial properties, and, particularly the redox-mediation properties, of the modified electrodes are influenced by the preparations conditions of the layers. Both the nature of the aryl layers termini and the barrier properties of the anchoring layers are expected to strongly determine the properties of the resulting modified electrodes. The electroreduction of the two diazonium salts used in that work were conducted at two different electrolysis potentials, yielding four anchoring platforms with different blocking abilities and different functional groups. Careful characterization of the somodified electrodes was carried out through AFM and cyclic voltammetry analyses. A particular focus is made on the blocking and/or catalytic properties of the ferrocenyl-modified electrodes. The experimental conditions used for the fabrication of the anchoring platform will produce thick multilayered films. ${ }^{29}$ It follows that high local concentrations of catalytic sites should be obtained with three-dimensional dispersion of the sites as opposed to the twodimensional arrangement prevailing at monolayer derivatized surfaces. ${ }^{30}$ Hence, efficient catalytic properties with the immobilized ferrocene could be reasonably expected. However, this supposes a strict control of charge transfer process at the redox-active layer/solution interface in order to favor the redox mediation. While difficulties related to the rates of free redox probes (substrate) diffusion and charge propagation might obviously decrease the catalytic efficiency, other phenomena such as (1) permeation of free redox probes into the film and electron transfer at bare surface or (2) diffusion of the free redox species inside 
pinhole or defect site and electron transfer at the bare surface are susceptible to hinder the redox mediation process as alternative mechanisms for the charge-transfer process. ${ }^{31}$ The redox-mediation properties of the ferrocenyl-modified electrodes were examined in relation with the preparation conditions of their corresponding anchoring layers and by varying the size and redox potentials of the employed probes. Remarkably, the different behaviours that were evidenced were not only dependent on the blocking properties of the anchoring platform but also on the size of the probes.

\section{Experimental Section}

Chemicals. Oxalyl chloride (98\%), pyridine (99\%) and triethylamine (99\%) were used as received from Aldrich. 4-aminophenylacetic acid and sodium nitrite (Acros), tetrabutylammonium hexafluorophosphate (Electrochemical grade, Fluka), paraphenylenediamine (Sigma), ferrocene carboxylic acid (Alfa Aesar), hydrochloric acid (Panseac), dichloromethane (SDS) were all used as received. The ferrocenylmethylamine was synthesized according to a published procedure. ${ }^{32}$ Various redox probes, exhibiting different standard potentials and different sizes were used for the electrochemical study of the modified electrodes. Bis(pentamethylcyclopentadienyl)iron (97\%) (DcMeFc), Ferrocene (98\%) (Fc), Ethynylferrocene (97\%) (EtFc), tri-p-tolylamine (97\%) (PTA) were used as received from Aldrich. 1,1'-dimethylferrocene (97 \%) (diMeFc) was purchased from Alfa Aesar. Ruthenium complex trans- $\left(\eta^{2}-\mathrm{dppe}\right)_{2} \mathrm{Ru}(-\mathrm{C} \equiv \mathrm{C}-\mathrm{Ph})_{2} \quad$ (Ru1) was obtained as previously described. ${ }^{33}$

Electrode Preparation before Modification. Working electrodes made of glassy carbon of diameter $3 \mathrm{~mm}$ were obtained from $\mathrm{CH}$ Instruments (Austin, TX). The glassy carbon electrode surfaces were polished successively with SiC paper $5 \mu \mathrm{m}$ (Struers), DP-Nap paper 1 $\mu \mathrm{m}$ (Struers) with $\mathrm{Al}_{2} \mathrm{O}_{3} 0.3 \mu \mathrm{m}$ slurry (Struers). After each polishing step, the electrode was thoroughly washed with ultrapure water $(18.2 \mathrm{M} \Omega \mathrm{cm})$. The surface cleaning was checked by recording a cyclic voltammogram of aqueous potassium ferrocyanide.

Electrode Modification. Modification of glassy carbon surface by electrochemical reduction of in situ generated diazonium was carried out at room-temperature. $\mathrm{NaNO}_{2}$ (final concentration $38 \mathrm{mmol} . \mathrm{L}^{-1}$ ) was added to the aqueous electrolytic solution containing 20 mmol. $\mathrm{L}^{-1} p$-phenylenediamine or 4-aminophenylacetic acid and $0.5 \mathrm{~mol} . \mathrm{L}^{-1} \mathrm{HCl}$ under stirring. The modification was achieved potentiostatically during $300 \mathrm{~s}$ at $-0.2 \mathrm{~V}$ or $-1.0 \mathrm{~V}$, depending on the desired layer thicknesses. After modification, the electrodes were rinsed with ultrapure water and freshly distilled dichloromethane. 
The subsequent ferrocenyl functionalization was carried out according two very similar routes, either with the modified carboxylic acid surface or with ferrocene carboxylic acid. The phenylacetic acid-modified surfaces were heated under reflux with 42 mmol. $\mathrm{L}^{-1}$ oxalyl chloride and 4 mmol. $\mathrm{L}^{-1}$ pyridine in distilled $\mathrm{CH}_{2} \mathrm{Cl}_{2}$. After 1 hour, all volatiles were removed under reduced pressure, then a $\mathrm{CH}_{2} \mathrm{Cl}_{2}$ solution of $6 \mathrm{mmol} . \mathrm{L}^{-1}$ ferrocenylmethylamine was introduced under argon atmosphere with an excess of triethylamine. The system was allowed to react at room temperature for 3 hours. Similarly, $16 \mathrm{mmol} . \mathrm{L}^{-1}$ of ferrocene carboxylic acid, $84 \mathrm{mmol.L} \mathrm{L}^{-1}$ of oxalyl chloride and $8 \mathrm{mmol} . \mathrm{L}^{-1}$ of pyridine were heated under reflux for 1 hour. After removing of all volatiles under reduced pressure, the residue was dissolved in freshly distilled $\mathrm{CH}_{2} \mathrm{Cl}_{2}$ and the phenylenamino-modified surface was allowed to react in the mixture for 3 hours at room temperature in the presence of triethylamine.

Finally, the modified surfaces were thoroughly rinsed in freshly distilled dichloromethane, and high-purity ethanol for 20-30 min, under vigorous stirring, then dried with Ar.

Electrochemical characterization. The modified electrodes were characterized by cyclic voltammetry in $\mathrm{CH}_{2} \mathrm{Cl}_{2}$ containing 0.2 mol. $\mathrm{L}^{-1}$ tetrabutylammonium hexafluorophosphate in the absence or in the presence of redox probes. Electrochemical measurements were performed in a one-compartment cell using a platinum wire as a counter-electrode and a SCE electrode (Radiometer Analytical) as a reference electrode. Cyclic voltammetry was recorded using a potentiostat Autolab (PGSTAT20 from Eco-Chemie B.V. equipped with the GPES software).

The total surface coverage of active ferrocene centers $(\Gamma)$ can be derived from the Faraday's law (1).

$$
\Gamma=\frac{\mathrm{Q}}{\mathrm{n} F \mathrm{~A}}
$$

Here $\mathrm{Q}$ is the charge passed, $\mathrm{n}$ is the number of electrons exchanged, $\mathrm{F}$ the Faraday's constant and $\mathrm{A}$ the electrode area taken as the geometric area of the GC electrodes $\left(0.07 \mathrm{~cm}^{2}\right)$. Q is obtained from the integration of the area under the voltammetric peaks at low scan rates using the integration function of the Origin ${ }^{\circledR}$ software. ${ }^{34}$ Polynomial baselines can be solved and subtracted prior to the curve integration.

AFM. Images were performed directly on the glassy carbon electrodes with a PicoSPM II coupled with an interface PicoSCAN 2500 interfaced with a PC. The scanner used is a PicoSPM II $10 \mu \mathrm{m}$ with a NCH-R or NCL-R Scientec tips. Images were recorded with PicoSCAN software (version 5.3.3). 


\section{Results and discussion}

Preparation of the anchoring platforms on glassy carbon surfaces. Aryl-diazonium salts were in situ generated in acidic solutions containing sodium nitrite and aminophenyl acetic acid or para-phenylenediamine. ${ }^{10,35}$ The subsequent electrochemical reduction of the aryldiazonium was potentiostatically achieved at $-0.2 \mathrm{~V}$ and at $-1.0 \mathrm{~V}$ for $300 \mathrm{~s}$. The high arylamine concentration and the long electrolysis time were both chosen for producing thick multilayers. $^{29,36}$ The potential is also a parameter allowing to control the thickness of the layer. ${ }^{13}$ The films grafted at $-1.0 \mathrm{~V}$ are expected to be thicker and/or have weaker porosity than the films grafted at $-0.2 \mathrm{~V} .{ }^{12,35}$ AFM analyses were carried out to probe the electrode surface after the electrochemical reductions of aryl-diazonium salts. For the two different applied potentials, visual inspection of the grafted electrodes points to the formation of multilayers with a rather large surface roughness. It is reported that the grafting of the layers under similar conditions to those used in this work proceeds by nucleation and growth, leading to the formation of films in both two or three dimensions of carbon surfaces. ${ }^{12,36}$ Moreover, a bare GC has a microscopically rough surface, hence making unlikely the formation of well-ordered and close-packed monolayers on this surface. AFM measurements were performed to compare the thicknesses of the different deposited films by using the "scratching" technique. This technique first developed by McCreery and coll. provides a reliable estimation of the layers thicknesses. ${ }^{12}$ It consists in ploughing the organic layer with an AFM tip in contact mode. Then, profiling depth measurements of the ploughed areas in acoustic mode give the average thickness of the layer. The $\boldsymbol{A r}-\mathrm{CH}_{2} \mathbf{C O O H}$ layers obtained from the reduction of in situ generated phenyl acetic acid diazonium salts were estimated to be $\sim 10 \mathrm{~nm}$ thick when the reduction is held at $-0.2 \mathrm{~V}$ and $\sim 15 \mathrm{~nm}$ thick when the reduction potential is $-1.0 \mathrm{~V}$. Similarly, the thicknesses of the $\boldsymbol{A r}-\mathbf{N H}_{2}$ layers obtained from the reduction of the in situ generated aminophenyl diazonium salts were found to be $\sim 8 \mathrm{~nm}$ and $\sim 17 \mathrm{~nm}$ for layers deposited at $-0.2 \mathrm{~V}$ and $-1.0 \mathrm{~V}$, respectively. These values are consistent with the thicknesses of $\sim 20-25 \mathrm{~nm}$ reported by Kariuki and McDermott for multilayered films obtained through a potential step with long electrolysis time. ${ }^{29}$ In the following, the layers deposited at $-0.2 \mathrm{~V}$ will be designated as thin modified electrodes while those at $-1.0 \mathrm{~V}$ will be designated as thick modified electrodes. 
Electrochemistry of redox probes at the $\mathrm{Ar}-\mathrm{NH}_{2}$ and $\mathrm{Ar}-\mathrm{CH}_{2} \mathrm{COOH}$ anchoring films. The blocking behaviours of the anchoring films were investigated by electrochemical measurements in the presence of different electroactive probes: ferrocene derivatives (DcMeFc, diMeFc, Fc, EtFc), PTA and Ru1 exhibit a range of redox potentials that would frame those of the immobilised electroactive functions (Scheme 1). Ru1 was chosen for being a particularly large and bulky species that are unlikely to diffuse through the layers. ${ }^{37}$ A wellformed insulating film in which compact layers have no pinholes or defects blocks electron transfer. Accordingly the redox response of the probe is not observed. By contrast, a film, that is porous, contains defects (only a weak percentage is sufficient) or is not enough thick will allow electron transfer between the carbon surface and the probe but with an apparent slow rate. $^{38}$

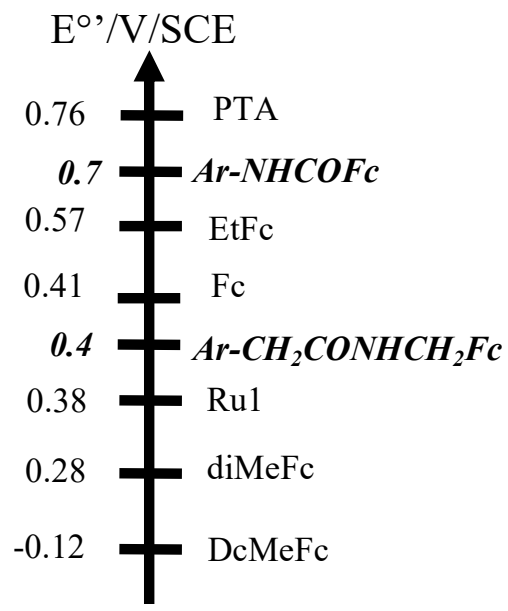

Scheme 1 : Redox probes used and their corresponding standard potentials. Potentials of the layers.

Figure 1 and Figure 2 display typical cyclic voltammetry in $\mathrm{CH}_{2} \mathrm{Cl}_{2}$ containing redox probes at bare and at modified electrodes for both thin and thick layers. As exemplified with Fc and PTA, the electrochemical response at $\mathbf{A r}-\mathrm{CH}_{2} \mathrm{COOH}$ thin electrodes is only hardly affected by the modification of the electrode: only a $10 \%$ decrease in anodic and cathodic peak currents, compared to those at bare electrode, could be observed, indicating that the film is loosely packed and defective. In contrast, a complete inhibition of the electrochemical response of the probes is observed at the thick layers. This agrees with the presence of a compact and dense layer that acts as a barrier. In principle, the blocking behaviour depends on the surface coverage because, as coverage increases, the number of defects and pinholes is reduced. ${ }^{35,38}$ 

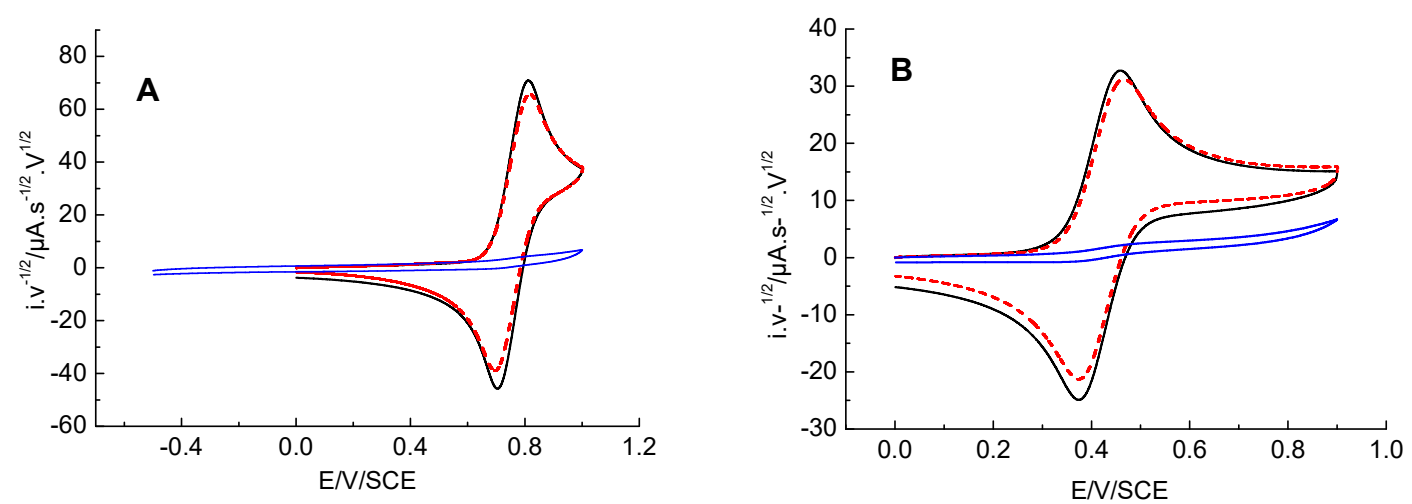

Figure 1. (A) Cyclic voltammetry in $0.2 \mathrm{M} \mathrm{Bu}_{4} \mathrm{NPF}_{6}+\mathrm{CH}_{2} \mathrm{Cl}_{2}$ of $\sim 1 \mathrm{mM}$ PTA at a bare carbon electrode (black solid line), at a $\mathrm{Ar}-\mathrm{CH}_{2} \mathbf{C O O H}$ "thin" modified electrode (red dashed line) and at a $\boldsymbol{A r}-\mathrm{CH}_{2} \mathbf{C O O H}$ "thick" modified electrode (blue solid line). (B) Same but CV of $1 \mathrm{mM}$ Fc.

A weaker blocking behaviour is detected at the $\mathbf{A r}-\mathbf{N H}_{2}$ thick modified electrodes (Figure 2). As shown here for PTA, a clear flattening of the CV response is observed at the modified electrodes, but a total suppression of the CV response cannot be evidenced as for the thick Ar$\mathrm{CH}_{2} \mathrm{COOH}$ layers.
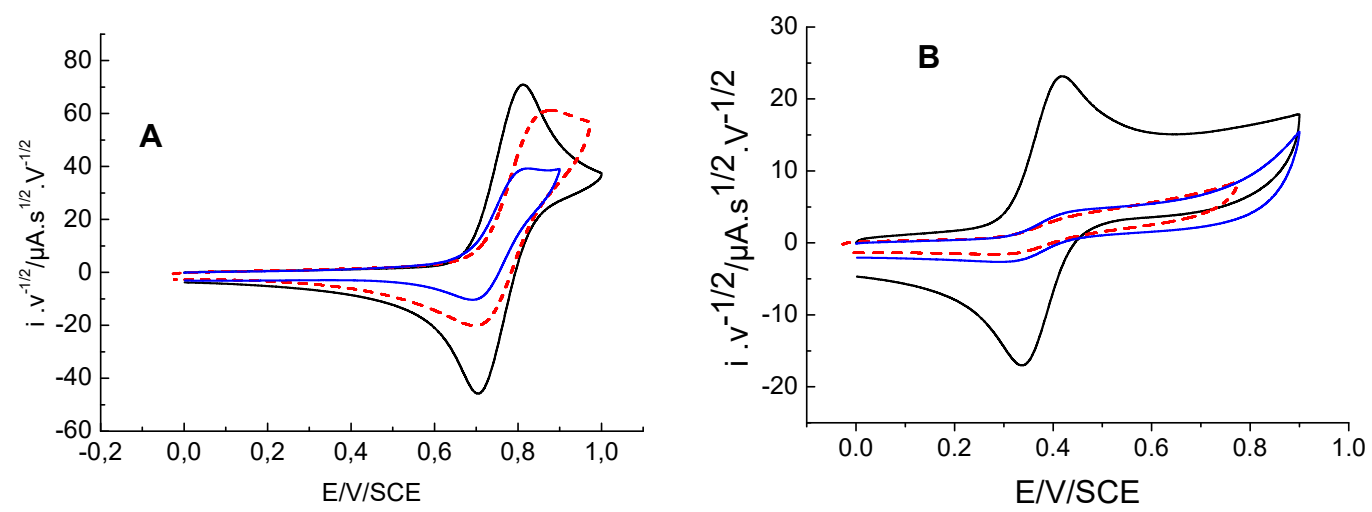

Figure 2. (A) Cyclic voltammetry in $0.2 \mathrm{M} \mathrm{Bu}_{4} \mathrm{NPF}_{6}+\mathrm{CH}_{2} \mathrm{Cl}_{2}$ of $\sim 1 \mathrm{mM}$ PTA at a bare carbon electrode (black solid line), at a $\mathbf{A r}-\mathbf{N H}_{2}$ "thin" modified electrode (red dashed line) and at a $\mathbf{A r}-\mathrm{NH}_{2}$ "thick" modified electrode (blue solid line). (B) same but CV of $0.5 \mathrm{mM}$ Ru1.

It can be observed that the CV responses at both the thick and thin $\mathbf{A r}-\mathrm{NH}_{2}$ films tend to be plateau-shaped (Figure 2). This observation suggests that the electrochemical response probably originates from small pinholes within the film. In the case of pinholes that are small and widely spaced, relatively to the diffusion layer thickness, they could act as a collection of non-overlapping ultramicroelectrodes and a pure S-shaped voltammogram would be 
obtained. ${ }^{39}$ The shape of the cyclic voltammogram is thus governed by four parameters, including the fraction of pinholes coverage, the scan rate, the heterogeneous electron-transfer kinetics and the spacing between adjacent pinholes. ${ }^{39,40}$ The "true" situation is complicated because the pores can have different size and their distribution within the film may be not uniform. However, an almost total suppression of the electrochemical response, at both the thin and the thick films, is observed when the bulky Ru1 redox probe is used (insert in Figure 2). However, it could be observed that the voltammograms corresponding to Ru1 are sigmoidal but with a very weak amplitude, thus confirming that the pinholes within the films are rather small and make easier the passage through the films of small probes (ferrocene derivatives or PTA) than of Ru1 molecules.

Introduction of Ferrocene at the anchoring platforms. The direct grafting of aminophenyl or phenylcarboxylic acid groups can make possible further chemical derivatization. The synthetic approach used in that work is aimed at developing a flexible and straightforward strategy that can be both applied to the $\boldsymbol{A r}-\mathrm{NH}_{2}$ and $\mathrm{Ar}-\mathrm{CH}_{2} \mathrm{COOH}$ films. The most popular strategy makes use of the carbodiimide chemistry for achieving an amidation between $\mathrm{NH}_{2}$ group and $\mathrm{COOH}$ moiety. This procedure very often involved carboxylic acid terminated layers, ${ }^{14,15,17,41-43}$ but some works described a successful procedure with $\mathrm{NH}_{2}$ termini, especially when primary amines are immobilized. ${ }^{16,19,44-46}$ Nevertheless, we were unable to bind ferrocene carboxylic acid with the $\boldsymbol{A r}-\mathbf{N H}_{2}$ layers using the NHS/EDC procedure, certainly because of the poor reactivity of the $\mathrm{NH}_{2}$ function substituting the aryl moiety. This result compelled us to develop another strategy as depicted on Scheme 2. The strategy consists in coupling a ferrocenoyl chloride compound onto an amino-terminated layer or, vice $v e r s a$, in generating the acyl chloride termini within the organic layer for further reaction with ferrocenylmethylamine. The activation through the acyl chloride is performed in situ with the use of oxalyl chloride. It was found to be a particularly versatile strategy since the chemical route can be applied to surface-reactive species as well as to reactive species in solution. Moreover, the synthetic approach is proved to be highly efficient because it allows a facile reaction with the aniline function which is poorly nucleophilic. 

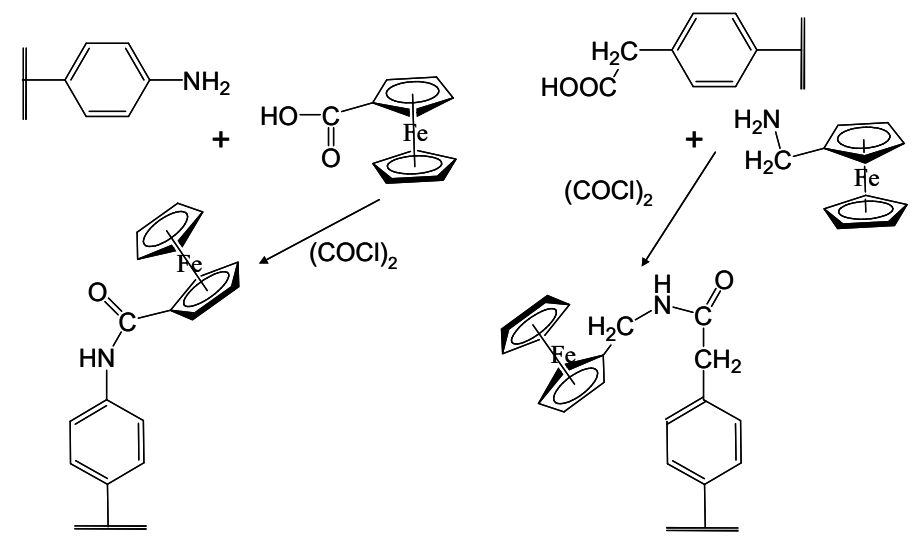

Scheme 2. Schematic representation of the "second step" used for immobilizing the ferrocene centers. The chemical attachment of ferrocene to $\boldsymbol{A r}-\mathbf{N H}_{2}$ (left) or $\boldsymbol{A r}-\mathrm{CH}_{2} \mathrm{COOH}$ (right) films yields the $\mathrm{Ar}-\mathrm{NHCOFc}$ and $\mathrm{Ar}-\mathrm{CH}_{2} \mathrm{CONHCH} \mathrm{HFc}_{2}$ modified electrodes, respectively.

The CV of the resulting ferrocene-modified $\mathrm{Ar}-\mathrm{NH}_{2}$ and $\mathrm{Ar}-\mathrm{CH}_{2} \mathrm{COOH}$ surfaces exhibit well-defined oxidation and reduction peaks corresponding to the ferrocene/ferrocenium couple (Figure 3). The redox systems are centered at $0.7 \mathrm{~V} / \mathrm{SCE}$ and $0.4 \mathrm{~V} / \mathrm{SCE}$ for the $\boldsymbol{A r}$ NHCOFc and $\mathrm{Ar}-\mathrm{CH}_{2} \mathrm{CONHCH} \mathrm{H}_{2} \mathrm{Fc}$ modified electrodes, respectively. These redox potentials closely correspond to those observed for ferrocene carboxylic acid and ferrocene dissolved in $\mathrm{CH}_{2} \mathrm{Cl}_{2}$, respectively. As expected for surface-immobilized redox species, the peak currents vary linearly as a function of the scan rates in the range $0.02-2.0 \mathrm{~V} \mathrm{~s}^{-1}$. ${ }^{47}$ The peak-to-peak separations $\Delta \mathrm{Ep}$ were between 35 and $64 \mathrm{mV}$ (at $0.2 \mathrm{~V} \mathrm{~s}^{-1}$ ). These $\Delta \mathrm{Ep}$ values are larger than the theoretical $0 \mathrm{mV}$ separation for fully reversible surface-confined species, but are in agreement with others reports in which electrons must pass through thin redoxfunctionalized films. ${ }^{21,48-51}$ Interestingly, the asymmetry of the immobilized ferrocene system is more marked at the thicker $\boldsymbol{A r}-\mathrm{CH}_{2} \mathrm{CONHCH}_{2} \mathrm{Fc}$ or $\boldsymbol{A r}-\mathrm{NHCOFc}$ modified electrodes, indicating that the electron transfer at the thick layers is slower than that at the thin layers. ${ }^{47}$ Moreover, the full width at half maximum (fwhm) is found larger $(120-140 \mathrm{mV})$ than the 91 $\mathrm{mV}$ predicted theoretically for an ideal reversible confined-redox system, ${ }^{52,47}$ indicating that ferrocene units are not all exactly in the same chemical "environment". 

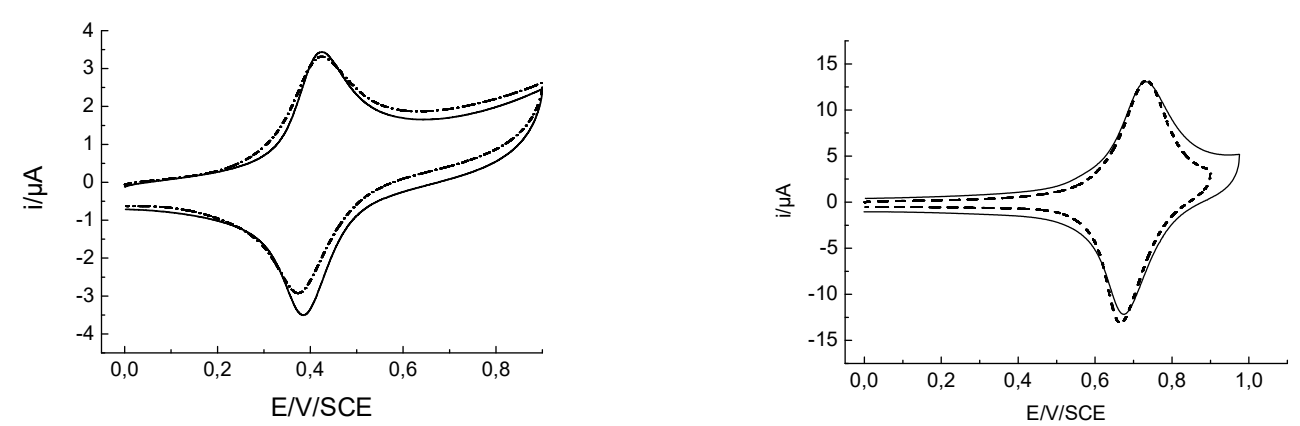

Figure 3. Cyclic voltammograms at $0.2 \mathrm{~V} \mathrm{~s}^{-1}$ of ferrocenyl-functionalized $\boldsymbol{A r}-\mathrm{CH}_{2} \mathrm{COOH}$ (left) and $\mathbf{A r}-\mathrm{NH}_{2}$ (right) films at thin (solid line) and thick (dashed line) layers in $\mathrm{CH}_{2} \mathrm{Cl}_{2}+$ $0.2 \mathrm{M} \mathrm{Bu}_{4} \mathrm{NPF}_{6}$.

The total surface coverage of active ferrocene centers $(\Gamma)$ for thin and thick modified electrodes and the thicknesses obtained from "scratching" of the redox-functionalized layers are gathered in Table 1. Remarkably, the ferrocene surface coverage is fully identical at thick and thin layers for the $\boldsymbol{A r}-\mathbf{N H C O F c}$ layer, on one hand, and for the $\boldsymbol{A r}-\mathrm{CH}_{2} \mathrm{CONHCH}_{2} \mathrm{Fc}$ layer, on the other hand. This suggests that the coupling reaction to ferrocene units only occurs at the upper layers of each type of films. The ferrocene surface coverages at $\boldsymbol{A r}$ $\mathrm{NHCOFc}$ are roughly four times higher than those at $\mathbf{A r}-\mathrm{CH}_{2} \mathbf{C O N H C H} \mathrm{H}_{2} \mathbf{F c}$. Two reasons might be invoked to explain this discrepancy: first, a difference in the anchoring layers structure, and particularly the fact that the $\mathbf{A r}-\mathbf{N H}_{2}$ films were found more porous than the $\boldsymbol{A r}$ $\mathrm{CH}_{2} \mathbf{C O O H}$ layers (vide infra), and second, the high sensitivity of the acyl chloride function towards water traces. ${ }^{53,54}$ Considering that ferrocene molecules are spheres of diameter $6.6 \AA$, the maximum ferrocene surface concentration for a monolayer has been reported to be about $4.5 \times 10^{-10} \mathrm{~mol} \mathrm{~cm}$, assuming a hexagonal closest-packing of the ferrocene molecules. ${ }^{43} \mathrm{As} \mathrm{a}$ result, the surface coverage determined for our films roughly correspond to 1.5 to 5 times the ferrocene monolayer coverage, depending on the nature of the films. Surface coverage values exceeding one monolayer have been already reported, ${ }^{14,19,48}$ and could be explained by the roughness of the GC electrode that contributes to increase the available surface with respect to the geometrical surface. In the present work, it is also likely that the presence of defects and pores within the films allows formation of multilayers of ferrocene. As shown above, the anchoring aryl layers contain pores large enough to let molecules like ferrocene go through the film. Therefore, this porous structure may allow the subsequent coupling of ferrocene to occur in both the two or three dimensions of the anchoring films, but probably still at the upper layers where the penetration is the easiest. AFM measurements qualitatively support this proposition. The topographic images of the surfaces after the chemical coupling displayed 
a marked sponge-like aspect with a clear increase of the roughness, suggesting that the chemical coupling disturbed the organisation and the compactness of the layers. For any of the films considered, the increase of thicknesses before and after the chemical coupling of ferrocene units is about 4-5 nm (Table 1). The increase of the thicknesses is higher than that could be expected from a calculation with the ferrocene surface coverage values. Indeed, 1 $\mathrm{nm}$ to $3.3 \mathrm{~nm}$ of thickness increase should be (roughly) obtained (from a simple stacking of ferrocene units, with ferrocene considered as spheres of $0.66 \mathrm{~nm}$ diameter). These observations point to a decrease of the film compactness after chemical coupling, ${ }^{55,56}$ and could be also fully consistent with the attachment of ferrocene centers in both the two or three dimensions of the anchoring layers.

These results are also compatible with the electrochemical characteristics of the immobilized redox system as reported above. The deviations from ideality we noticed could be then assigned to interactions between the redox centers which are then highly concentrated at the electrode surface and to lateral diffusion of electrons and charge at these rough surfaces. ${ }^{14,47,48}$

Table 1. Estimation of the ferrocene surface coverage for the different films and film thicknesses

\begin{tabular}{|c|c|c|}
\hline & $\Gamma\left(\mathrm{mol} \mathrm{cm} \mathrm{cm}^{-2}\right)$ & Thickness (nm) \\
\hline $\mathrm{Ar}-\mathrm{CH}_{2} \mathrm{CONHCH}{ }_{2} \mathrm{Fc}$ thin film & $5.3 \times 10^{-10}$ & $\sim 15$ \\
\hline $\mathrm{Ar}-\mathrm{CH}_{2} \mathrm{CONHCH}{ }_{2} \mathrm{Fc}$ thick film & $5.4 \times 10^{-10}$ & $\sim 20$ \\
\hline Ar-NHCOFc thin film & $2.3 \times 10^{-9}$ & $\sim 12$ \\
\hline Ar-NHCOFc thick film & $2.2 \times 10^{-9}$ & $\sim 22$ \\
\hline
\end{tabular}

Electrochemistry of redox probes at $\mathrm{Ar}-\mathrm{NHCOFc}$ and $\mathrm{Ar}-\mathrm{CH}_{2} \mathrm{CONHCH}_{2} \mathrm{Fc}$ electrodes. The interfacial properties of the ferrocene-modified electrodes were further investigated by the electrochemistry of redox probes in solution. It could be evidenced that the behaviours of the different modified electrodes strongly depend on the initial blocking properties of the anchoring platforms.

Thick Ar- $\mathrm{CH}_{2} \mathrm{CONHCH} \mathrm{H}_{2}$ c layers. We examined the electrochemical behaviour of the free redox probes at the thick $\mathrm{Ar}-\mathrm{CH}_{2} \mathrm{CONHCH} \mathrm{H}_{2} \boldsymbol{F c}$ modified electrode, for which the anchoring platform $\mathrm{Ar}-\mathrm{CH}_{2} \mathrm{COOH}$ exhibited the strongest blocking properties. As depicted on Figure 4A, the CV curve of DcMeFc shows only one irreversible peak located nearby the potential 
corresponding to that of the attached ferrocene, with a current amplitude fairly identical to that for DcMeFc in solution at a bare electrode. Concerning the other redox probes, progressive changes in the shape of the resulted voltammograms are noteworthy. As the corresponding standard potentials of the free probes increase, being closer then higher than the potential corresponding to the attached ferrocene units (Scheme 1), the redox layer tends acting as a barrier: the CV curves show a considerable flattening of the peak (Figure 4B) that becomes more and more pronounced to the point of vanishing, depending on the redox probes considered. Thus, the voltammogram corresponding to PTA only displays the electrochemical signal corresponding to the immobilized ferrocene moieties (Figure 4C). These observations are in full agreement with a redox-mediated process. The oxidation of DcMeFc occurs from a reaction between electrogenerated attached ferrocenenium with DcMeFc in solution. ${ }^{30,57}$. This process is well fitted with a catalytic mechanism where the catalysis is demonstrated via an increase in the mediator (or catalyst) wave (the immobilized ferrocene) accompanied by loss of reversibility. The recorded catalytic current is due to the enhanced electroactivity of the redox layers. ${ }^{30,58-62}$ The behaviour as evidenced for DcMeFc at the thick $\boldsymbol{A r}$ $\mathrm{CH}_{2} \mathrm{CONHCH} \mathrm{H}_{2} \mathrm{Fc}$ is characteristic of "total catalysis" EC mechanism that is kinetically controlled by the diffusion of DcMeFc to the modified electrode rather than its consumption. ${ }^{63,40}$ This mechanism is thermodynamically promoted providing that the free redox probes have an apparent standard potential below that of the redox centers immobilized in the layers. ${ }^{40}$ The model predicts the absence of charge transfer and of electrochemical signals when the free redox probes have a potential above that of the immobilized catalysts. Accordingly, no electrochemical signal could be detected in the case of PTA. Interestingly, the results obtained with the varied redox probes show that the catalytic activity is operative only if the potential of the immobilized redox centers is significantly more positive than the free redox probes standard potential in the same medium. Thus, the mediation could not be evidenced for diMeFc or Fc, indicating that the mediated oxidation is a uphill reaction, ${ }^{30}$ requiring a driving force largely superior to $120 \mathrm{mV}^{64} \mathrm{~A}$ further observation of the voltammogram reveals that the mediated oxidation of DcMeFc at thick $\mathrm{Ar}-\mathrm{CH}_{2} \mathrm{CONHCH}_{2} \mathrm{Fc}$ is strongly positively-shifted (even more positive shifted at the thick film (Figure 4A) than at the thin film (Figure 5A)). A similar behaviour has been already reported for the mediated oxidation of ferrocyanide species occurring at monolayers containing ferrocene mediators ought to a biotine-streptavidin interaction or at monolayers containing ferrocenyl dendrimers. ${ }^{65,66}$ This behaviour indicates that the mediated oxidation is kinetically less efficient in the case of the thick film. ${ }^{40}$ We could ascribe this lost of catalytic efficiency to a 
difficulty in the charge transport inside the film since both the nature of the film and of the redox probe remain the same at thick and thin layers. When making thick anchoring layers, we found that the coupling of ferrocenyl groups is restricted to the upper layers. It results that the density of redox groups is lower within the thick film and, thus that the charge transfer from the solution-film interface to the electrode substrate is less efficient.
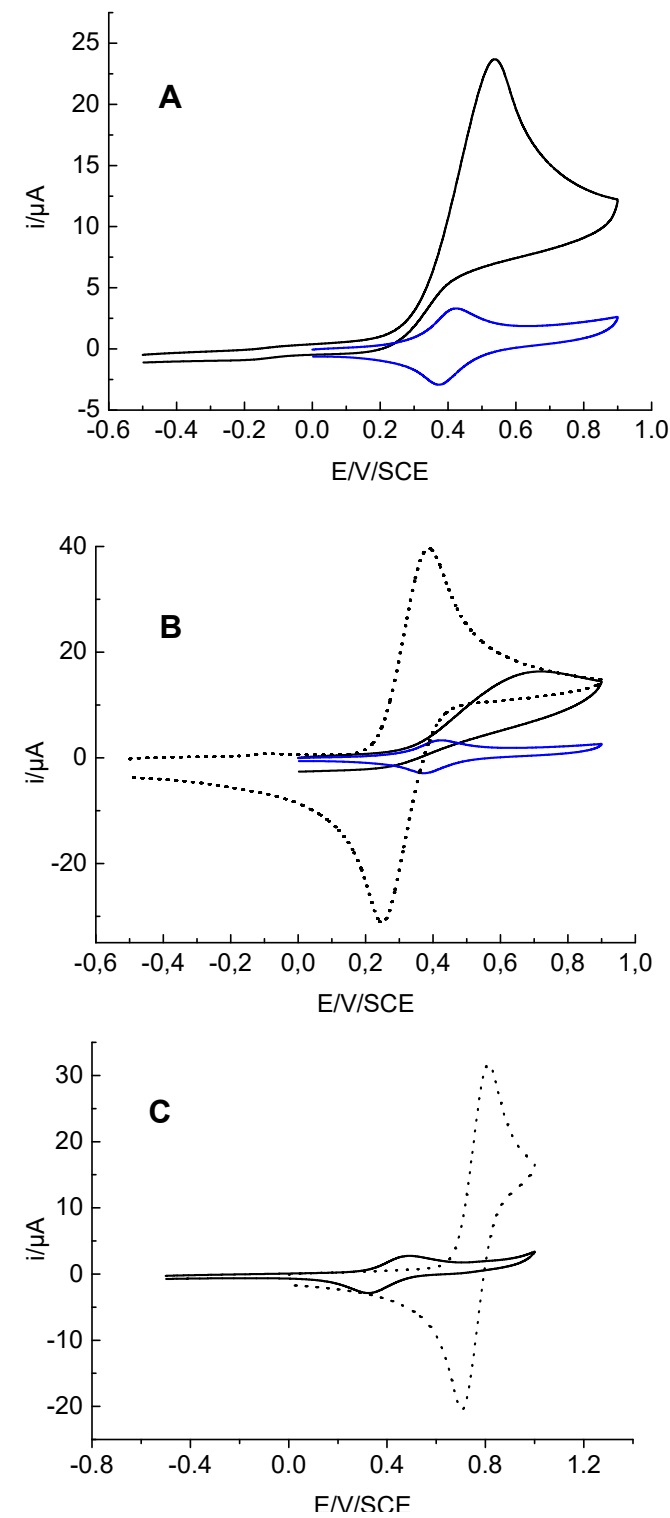

Figure 4. Cyclic voltammetry in $0.2 \mathrm{M} \mathrm{Bu}_{4} \mathrm{NPF}_{6}+\mathrm{CH}_{2} \mathrm{Cl}_{2}$ of thick $\boldsymbol{A r}-\boldsymbol{C H}_{2} \boldsymbol{C O N H C H} \boldsymbol{H}_{2} \boldsymbol{F c}$ film (A) in the absence (blue solid line) and in the presence of $1 \mathrm{mM} \mathrm{DcMeFc}$ (black solid line), (B) in the absence (blue solid line) and in the presence of $1 \mathrm{mM} \mathrm{diMeFc} \mathrm{(black} \mathrm{solid}$ line) and (C) in the presence of $1 \mathrm{mM}$ PTA (black solid line). For comparison purpose, CVs of $1 \mathrm{mM}$ diMeFc (B) and 1mM PTA (C) at bare GC electrode were also added (dotted line). Scan rate $0.2 \mathrm{~V} \mathrm{~s}^{-1}$. 
Thin $\mathrm{Ar}-\mathrm{CH}_{2} \mathrm{CONHCH}{ }_{2} \mathrm{Fc}$ layers. The cyclic voltammetry at the thin $\mathrm{Ar}-\mathrm{CH}_{2} \mathrm{CONHCH}_{2} \mathrm{Fc}$ layers is significantly different from that at the corresponding thick ones. As exemplified on Figure 5A with diMeFc, the voltammogram at the thin layers electrodes exhibited a peakshaped curve at the corresponding standard potential of the free redox probes similar to those observed at the bare electrode. The voltammograms of Fc, EtFc and PTA exhibited similar features. This result is consistent with the absence of blocking properties found for the thin $\mathrm{Ar}-\mathrm{CH}_{2} \mathrm{COOH}$ anchoring layer. However, worth is noting that DcMeFc behaved rather differently (Figure 5B). A small sigmoidal signal is obtained at the "regular" standard potential of $\mathbf{D c M e F c} / \mathbf{D c M e F c}^{\bullet+}(-0.12 \mathrm{~V})$ together with an irreversible peak positively shifted to $0.28 \mathrm{~V}$ (Figure 5B). The peak current magnitude corresponds to the signal obtained for DcMeFc in solution at a bare electrode. It is still discernable on the right side of this peak the reversible redox system due to the attached ferrocene. A redox mediated reaction for the oxidation of DcMeFc may also be invoked to explain the presence of the positively-shifted irreversible peak. Hence, the electrochemical oxidation of DcMeFc originates from two phenomena, i.e. redox mediation and electronic transfer at pinholes between the electrode and the free redox probe as evidenced through the presence of the sigmoidal wave.
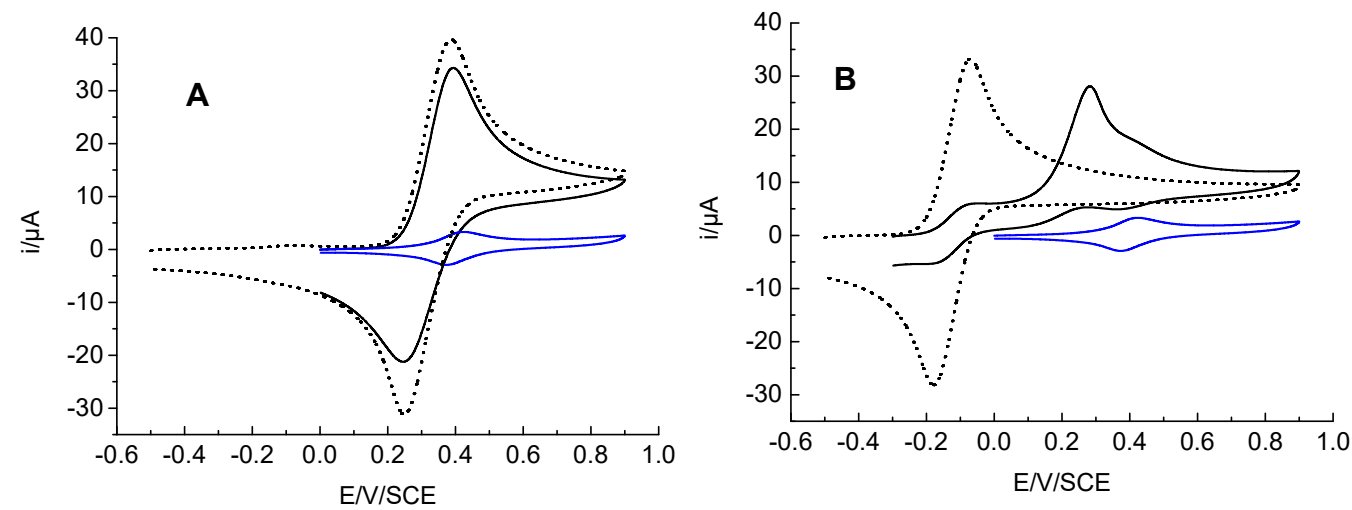

Figure 5. Cyclic voltammetry in $0.2 \mathrm{M} \mathrm{Bu}_{4} \mathrm{NPF}_{6}+\mathrm{CH}_{2} \mathrm{Cl}_{2}$ of thin $\boldsymbol{A r}-\boldsymbol{C H}_{2} \boldsymbol{C O N H C H} \boldsymbol{C H}_{2} \boldsymbol{F}$ film (A) in the absence (blue solid line) and in the presence of $1 \mathrm{mM}$ diMeFc (black solid line), (B) in the absence (blue solid line) and in the presence of $1 \mathrm{mM} \mathrm{DcMeFc}$ (black solid line). In dotted line CVs of $1 \mathrm{mM}$ diMeFc (A) and 1mM DcMeFc (B) at bare GC electrode were displayed. Scan rate $0.2 \mathrm{~V} \mathrm{~s}^{-1}$.

Thin and thick Ar-NHCOFc layers, case of the bulky Ru1 redox probe. A very similar electrochemical behaviour showing the coexistence of permeation and catalytic phenomena is also observed at the $\boldsymbol{A r}-\mathbf{N H C O F c}$ layers but only for the bulky Ru1 probe. Contrariwise to the latter layers, there is no significant difference in the electrochemical response of the probe between the thick and the thin layers. First, a sigmoidal rather peak-shaped voltammogram is 
obtained at $0.38 \mathrm{~V}$ which is the standard potential of Ru1, indicating that the electrochemical response is due to pinholes and/or defects within the layers. Importantly, the corresponding signal is significantly weaker than that obtained at a bare surface but, however, larger than that recorded for Ru1 at the $\mathbf{A r}-\mathbf{N H}_{2}$ layers (Figure 2B). This observation suggests that the lost of compactness and organisation due to the chemical functionalization in the $\boldsymbol{A r}-\mathbf{N H}_{2}$ layers is of sufficient amplitude to allow permeation of a small amount of the probes within the films. Second, a shoulder-like irreversible peak located at $\sim 0.63 \mathrm{~V}$ is observable on the left-side of the attached ferrocene redox system (Figure 6A). The current is of the same amplitude than that of the Ru1 probe signal at a bare electrode. These observations suggest that the Ru1 oxidation is also occurring according to a mediated scheme involving the attached ferrocene units (EC mechanism). Regarding the relative standard potentials for the immobilized ferrocene in the $\boldsymbol{A r}$-NHCOFc layers and the free Ru1, the forward mediation is thermodynamically favorable because the ferrocenium is a strong enough oxidant to oxidize Ru1. In contrast, the reverse reaction is thermodynamically unfavorable because ferrocene is not a strong enough reductant to achieve the reduction of the Ru1 oxidized form, resulting in the irreversibility of the wave. This behaviour is strongly similar to that observed onto the thin $\mathrm{Ar}-\mathrm{CH}_{2} \mathrm{CONHCH} \mathrm{H}_{2} \mathrm{~F}$ with the DcMeFc as a redox probe. The major point of such behaviour is the demonstration that when only a small part of the redox probe is able to permeate through the layers as observed for both $\mathrm{DcMeFc}$ and $\mathrm{Ru} 1$ onto $\mathrm{Ar}-\mathrm{CH}_{2} \mathrm{CONHCH}_{2} \mathrm{Fc}$ and $\mathrm{Ar}$ $\mathrm{NHCOFc}$, respectively, the redox-mediation occurs to allow the rest of the probes exchanging electrons with the layers.

Thin and thick Ar-NHCOFc layers, case of the ferrocene derivatives and PTA probes. Figure 6B shows the $\mathrm{CV}$ curves for $\mathbf{F c}$, and closely-related $\mathrm{CV}$ were obtained for the other electroactive probes. At $\mathrm{E} \approx 0.4 \mathrm{~V}$, the $\mathrm{CV}$ displays the characteristic shape for a diffusioncontrolled reversible redox process while the redox peaks located at $\sim 0.7 \mathrm{~V}$ obviously corresponds to that of the reversible redox system of the immobilized ferrocene/ferrocenium couple. This corresponds to the reversible oxidation of Fc and resembles to that obtained at a bare GC electrode, indicating that the electron-transfer process occurs at a largely porous layer. As outlined above, the anchoring platforms displayed actually weak blocking effects towards the smallest probes. Nevertheless, these observations as exemplified on Figure 6B confirm that the blocking properties of the Ar-NHCOFc layers become weaker than those of their corresponding anchoring $\mathbf{A r}-\mathbf{N H}_{2}$ layers, due the subsequent chemical coupling. Because the permeation of the probes within the film is total, no redox-mediation is observed. 

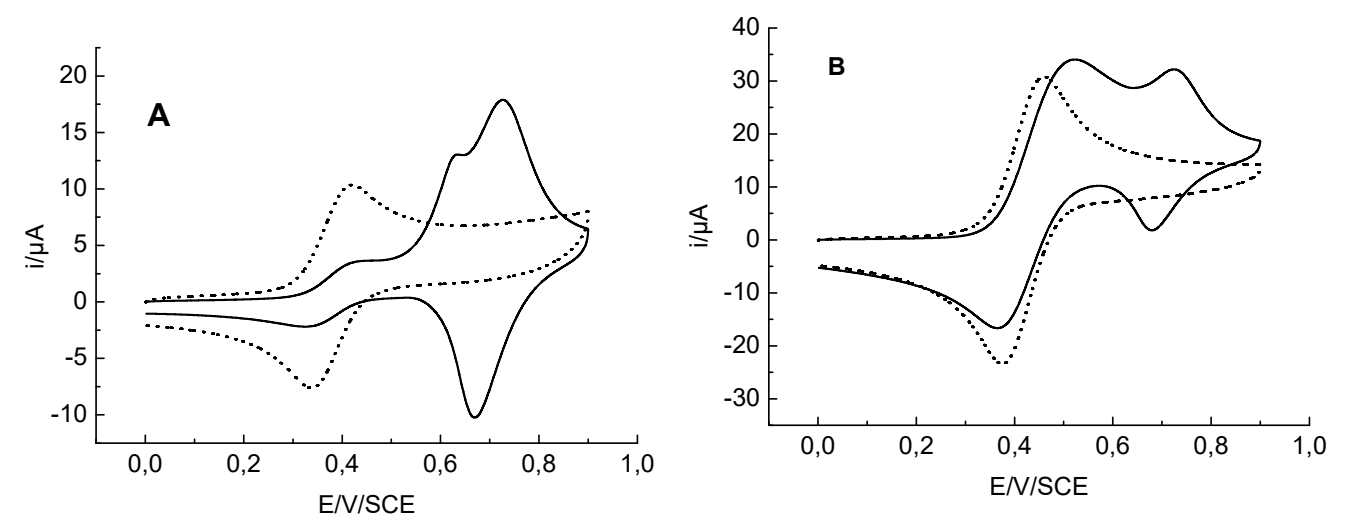

Figure 6. Cyclic voltammetry in $0.2 \mathrm{M} \mathrm{Bu}_{4} \mathrm{NPF}_{6}+\mathrm{CH}_{2} \mathrm{Cl}_{2}$ at a bare $\mathrm{GC}$ electrode (dotted line) and at $\boldsymbol{A r}-\mathbf{N H C O F}$ thick modified electrode (solid line). (A) $0.5 \mathrm{mM}$ Ru1 (B) $1 \mathrm{mM}$ Fc. Scan rate $0.2 \mathrm{~V} \mathrm{~s}^{-1}$.

\section{Conclusion}

A versatile strategy based on the reactivity of acyl chloride function for amino groups was successfully applied to anchoring aryl layers with either amino or carboxylic termini to covalently bind ferrocene centers at glassy carbon surfaces. The versatility of the procedure is demonstrated by the fact that it can be applied either to surface-reactive end groups or to reactive species in solution. The covalent binding of ferrocene units was restricted to the upper layers of the underlying aryl films. The robust anchoring platforms of different thicknesses were easily introduced thanks to the electrochemical reduction of aryldiazonium salts that were in situ generated. As expected, the blocking properties of the anchoring layers towards free redox probes were basically different, depending on the thickness but also on the layer nature. Only the thick layers of phenyl acetic acid act as a barrier towards electron transfer. The blocking properties of the underlying layers were found to strongly influence the catalytic properties of the subsequent ferrocenyl-functionalized layers. A mediated reaction (total catalysis) between free redox probes and immobilized redox centers could be observed, either as the unique apparent process or as a less straightforward behaviour with the coexistence of two distinct phenomena, redox mediation and ET at pinholes. This is achieved by using a thick, compact and dense anchoring film or by employing a large-sized probe. 
Acknowledgements. This work was partly supported by the Agence Nationale de la Recherche (ANR), project ANR-06-BLAN0296-REEL. D.Z. thanks Région Bretagne for Ph. D. grant.

Supporting Information Available: AFM images and cyclic voltammetry at ferrocenyl-functionalized layers. This information is free of charge via the internet at http://pubs.acs.org/.

\section{Notes and references}

(1) Love, J. C.; Estroff, L. A.; Kriebel, J. K.; Nuzzo, R. G.; Whitesides, G. M. Chem. Rev. 2005, 105, 1103-1169.

(2) Delamar, M.; Hitmi, R.; Pinson, J.; Savéant, J. M. J. Am. Chem. Soc. 1992, $114,5883-5884$.

(3) Liu, Y.-C.; McCreery, R. L. J. Am. Chem. Soc. 1995, 117, 11254-11259.

(4) Saby, C.; Ortiz, B.; Champagne, G. Y.; Bélanger, D. Langmuir 1997, 13, 68056813.

(5) Bahr, J. L.; Yang, J.; Kosynkin, D. V.; Bronikowski, M. J.; Smalley, R. E.; Tour, J. M. J. Am. Chem. Soc. 2001, 123, 6536-6542.

(6) Lomeda, J. R.; Doyle, C. D.; Kosynkin, D. V.; Hwang, W.-F.; Tour, J. M. J. Am. Chem. Soc. 2008, 130, 16201-16206.

(7) Downard, A. J. Electroanalysis 2000, 12, 1085-1096.

(8) Pinson, J.; Podvorica, F. I. Chem. Soc. Rev. 2005, 34, 429-439.

(9) Gooding, J. J. Electroanalysis 2008, 20, 573-582.

(10) Lyskawa, J.; Bélanger, D. Chem. Mater 2006, 18, 4755-4763.

(11) Baraton, S.; Bélanger, D. Electrochim. Acta 2008, 53, 6961-6967.

(12) Anariba, F.; DuVall, S. H.; McCreery, R. L. Anal. Chem. 2003, 75, 3837-3844.

(13) Downard, A. J. Langmuir 2000, 16, 9680-9682.

(14) Boland, S.; Barrière, F.; Leech, D. Langmuir 2008, 24, 6351-6358.

(15) Radi, A.-E.; Lates, V.; Marty, J.-L. Electroanalysis 2008, 20, 2557-2562.

(16) Griveau, S.; Mercier, D.; Vautrin-U1, C.; Chaussé, A. Electrochem. Commun. 2007, 9, 2768-2773.

(17) Liu, G.; Böcking, T.; Gooding, J. J. J. Electroanal. Chem. 2007, 600, 335-344.

(18) Liu, G.; Liu, J.; Böcking, T.; Eggers, P. K.; Gooding, J. J. Chem. Phys. 2005, $319,136-146$.

(19) Vijaikanth, V.; Capon, J.-F.; Gloaguen, F.; Schollhammer, P.; Talarmin, J. Electrochem. Commun. 2005, 7, 427-430.

(20) Evrard, D.; Lambert, F.; Policar, C.; Balland, V.; Limoges, B. Chem. Eur. J. 2008, 14, 9286-9291.

(21) Harper, J. C.; Polsky, R.; Wheeler, D. R.; Brozik, S. M. Langmuir 2008, 24, 2206-2211. 
(22) Allongue, P.; Delamar, M.; Desbat, B.; Fagebaume, O.; Hitmi, R.; Pinson, J.; Savéant, J. M. J. Am. Chem. Soc. 1997, 119, 201-207.

(23) Duevel, R. V.; Corn, R. M. Anal. Chem. 1992, 64, 337-342.

(24) Chapman, R. G.; Ostuni, E.; Liang, M. N.; Meluleni, G.; Kim, E.; Yan, L.; Pier, G.; Warren, H. S.; Whitesides, G. M. Langmuir 2001, 17, 1225-1233.

(25) Sortino, S.; Petralia, S.; Conoci, S.; Di Bella, S. J. Am. Chem. Soc. 2003, 125, $1122-1123$.

(26) Yu, S. S. C.; Downard, A. J. Langmuir 2007, 23, 4662-4668.

(27) Plumeré, N.; Speiser, B. electrochim. Acta 2007, 53, 1244-1251.

(28) Lockett, M. R.; Carlisle, J. C.; Le, D. V.; Smith, L. M. Langmuir 2009, 25, $5120-5126$.

(29) Kariuki, J. K.; McDermott, M. T. Langmuir 2001, 17, 5947-5951.

8182.

(30) Andrieux, C. P.; Haas, O.; Savéant, J. M. J. Am. Chem. Soc. 1986, 108, 8175-

(31) By taking into account the large thicknesses of the underlying layers, the tunneling process can be discarded.

(32) Baramee, A.; Coppin, A.; Mortuaire, M.; Pelinski, L.; Tomavo, S.; Brocard, J. Bioorg. Med. Chem. 2006, 14, 1294-1302.

(33) Touchard, D.; Haquette, P.; Guesmi, S.; Le Pichon, L.; Daridor, A.; Toupet, L.; Dixneuf, P. H. Organomet. 1997, 16, 3640-3648.

2002 .

(34) Origin; 7.03 ed.; Origin Lab Corporation: Northampton, MA, USA, 1991-

(35) Baraton, S.; Bélanger, D. J. Phys. Chem. B 2005, 109, 24401-24410.

(36) Kariuki, J. K.; McDermott, M. T. Langmuir 1999, 15, 6534-6540.

(37) From calculations of energy minimization using PM3 method, the different redox molecules used in that work (ferrocene derivatives and PTA) were roughly estimated to be spheres of 8-10 $\AA$ of diameter while that of Ru1 was about 20-22 $\AA$.

(38) Downard, A. J.; Prince, M. J. Langmuir 2001, 17, 5581-5586.

(39) Amatore, C.; Savéant, J. M.; Tessier, D. J. Electroanal. Chem. 1983, 147, 3951.

(40) Savéant, J. M. Elements of Molecular and Biomolecular Electrochemistry: An Electrochemical Approach to Electron transfer Chemistry; John Wiley \& Sons: Hoboken, 2006.

(41) Fabre, B.; Hauquier, F. J. Phys. Chem. B 2006, 110, 6848-6855.

(42) Calvo-Munoz, M.-L.; Ehui-Avo Bile, B.; Billon, M.; Bidan, G. J. Electroanal. Chem. 2005, 578, 301-313.

(43) Seo, K.; Jeon, I. C.; Yoo, D. J. Langmuir 2004, 20, 4147-4154.

(44) Chrétien, J.-M.; Ghanem, M. A.; Bartlett, P. N.; Kilburn, J. D. Chem. Eur. J. 2008, 14, 2548-2556.

(45) Anne, A.; Blanc, B.; Moiroux, J.; Savéant, J. M. Langmuir 1998, 2368-2371.

(46) Frutos, A. G.; Brockman, J. M.; Corn, R. M. Langmuir 2000, 16, 2192-2197.

(47) Bard, A. J.; Faulkner, L. R. Electrochemical methods. Fundamentals and Applications. 2nd Edition; John Wiley \& Sons: New York, 2001.

(48) Buriez, O.; Labbé, E.; Pigeon, P.; Jaouen, G.; Amatore, C. J. Electroanal. Chem. 2008, 619-620, 168-175.

(49) Amatore, C.; Maisonhaute, E.; Schöllhorn, B.; Wadhawan, J. ChemPhysChem 2007, 8, 1321-1329.

(50) Uosaki, K.; Sato, Y.; Kita, H. Langmuir 1991, 7, 1510-1514.

(51) Wang, C.-L.; Mulchandani, A. Anal. Chem. 1995, 67, 1109-1114. 
(52) The ideal reversible system implies that no lateral interactions occur between the surface confined redox units and a rapid equilibrium is established with the electrode.

(53) Tsubokawa, N.; Kazuhisa, K.; Sone, Y. Polymer Bulletin 1987, 17, 87-93.

(54) Because a reaction between residual water and acyl chloride would impede further derivatization of the surface, this exposes much more the acyl chloride terminated layers than the ferrocene carboxylic acid. Indeed, the ferrocene carboxylic acid is introduced in a large excess in the reaction medium as compared to the exposed $-\mathrm{NH}_{2}$ functional groups. The presence of residual water traces may react with a small fraction of the ferrocenoyl species without interfering significantly with the surface reaction. Contrariwise the amount of acyl chloride termini on the grafted layers is weak, especially regarding the reagents or solvent we introduced. So this step needs to be performed under strict anhydrous conditions. For instance, we found that ferrocenemethylamine required being freshly synthesized and stored under vacuum before use since its orange crystals tend to associate with water molecules when left under air.

(55) Brooksby, P. A.; Downard, A. J. J. Phys. Chem. B 2005, 109, 8791-8798.

(56) Yu, S. S. C.; Downard, A. J. e-J. surf. Sci. Nanotech. 2005, 3, 294-298.

(57) Alleman, K. S.; Weber, K.; Creager, S. E. J. Phys. Chem. 1996, 100, 1705017058

(58) Andrieux, C. P.; Savéant, J. M. J. Electroanal. Chem. 1978, 93, 163-168.

(59) Andrieux, C. P.; Dumas-Bouchiat, J. M.; Savéant, J. M. J. Electroanal. Chem. $1981,123,171-187$.

(60) Zhang, J.; Anson, F. C. J. Electroanal. Chem. 1993, 348, 81-97.

(61) Xie, Y.; Anson, F. C. J. Electroanal. Chem. 1995, 384, 145-153.

(62) Merz, A.; Bachmann, H. J. Am. Chem. Soc. 1995, 117, 901-908.

(63) In this case, the homogeneous electron transfer is considered as the ratedetermining step.

(64) The oxidation of DcMeFc by the attached ferrocenium is a reaction with a driving force of $520 \mathrm{mV}$.

(65) Azzaroni, O.; Alvarez, M.; Mir, M.; Yameen, B.; Knoll, W. J. Phys. Chem. C 2008, 112, 15850-15859.

(66) Oh, S.-K.; Baker, L. A.; Crooks, R. M. Langmuir 2002, 18, 6981-6987. 